\title{
Tejidos que transitan en la escuela hoy: pedagogía/cuerpo/aprendizaje
}

\section{Woven that transit at school today: pedagogy/ body/ learn}

\author{
Diana Ortiz-Chalarca \\ Silvio Cardona-González \\ Universidad Católica de Manizales. Manizales, Colombia
}

\section{Resumen}

Objetivo: hilar comprensiones del bucle escuela/ aprendizaje desde posturas relacionantes con/en/a través del cuerpo, que se dan en la escuela de hoy. Método: en este artículo de revisión el camino se teje desde el pensamiento complejo como método, con un diseño de investigación que parte del vértice cuerpo como postura relacionante y sus entramados con el problema crucial del aprendizaje, en triángulos virtuosos articulados desde las comprensiones transdisciplinares/ complejas/ dinámicas/ sistémicas del ámbito educativo. Integra dimensiones empíricas y teóricas para religar desde la memoria y dónde se sitúa; un enfoque hologramático que relaciona la literatura y la experiencia desde diferentes ámbitos en comprensiones complejas para otras formas de vivir el cuerpo en la escuela. Discusión y Conclusiones: se plantea la necesidad social de transformar paradigmas educativos que han creado hábitos escolares limitando la experiencia de aprendizaje al segmentar procesos y vivencias en las personas. Se pretende ampliar las visiones de formadores de docentes, docentes y comunidad educativa en general para que evidencien el bioaprendizaje desde unas comprensiones cosmogónicas del cuerpo, dando paso a una pedagogía corporeizada consciente que permita que la enacción y la mediación actúen como camino para vivenciar la pedagogía desde el hacer.

Palabras clave: aprendizaje, cuerpo, complejidad, escuela.

\begin{abstract}
Objective: to spin understandings of the school / learning loop from positions related to / in / through the body, which occur in today's school. Method: in this review article, the path is woven from complex thinking as a method, with a research design that starts from the vertex of the body as a related posture and its frameworks with the crucial problem of learning, in virtuous triangles articulated from transdisciplinary understandings/ complex/ dynamic/ systemic in the educational field. It integrates empirical and theoretical dimensions to religion from memory and where isit; a hologrammatic approach that relates literature and experience from different fields in complex understandings for other ways of living the body at school. Discussion and Conclusions: the social need to transform educational paradigms that have created school habits that limit the learning experience by segmenting processes and experiences in people is raised. The aim is to expand the visions of teacher educators, teachers and the educational community in general so that they demonstrate biolearning from cosmogonic understandings of the body, giving way to a conscious embodied pedagogy that allows enaction and mediation to act as a way to experience pedagogy from doing.
\end{abstract}

Keywords: body, complexity, learning, school.
Open Access:

ISSN: $0124-2121$

E-ISSN: $2665-2420$

ARTÍCULO RESULTADO DE REVISIÓN

By Educación y Humanismo

Editor:

Dhayana Fernández Matos

Universidad Simón Bolívar

Correspondencia:

Diana Ortiz dianacarolina.o@me.com

Recibido: 11-03-2020

Aceptado: $30-07-2020$

En línea desde: $21-10-2020$

DOI:

10.17081/eduhum.22.39.3717 


\section{Introducción}

Entrelazar miradas para observar la escuela desde la complejidad implica encarnarse en la misma y desde su vértice tratar de comprenderla, hilar lo que dentro de sí teje: vidas humanas, y desde una sutileza subjetiva, reconocer los propósitos o despropósitos de este tejido, así, es como para esta revisión decidimos internarnos en las relaciones desde el cómo se articula cuerpo/aprendizaje explorados desde congruencias e incongruencias en movimiento como "compuertas evolutivas" (Najmanovich, 2008) en la escuela del presente.

La escuela hoy ha sido comprendida desde muchas investigaciones tratando de resolver su papel para la sociedad actual, en muchos casos, la investigación se ha situado en las posibles causas del fracaso escolar, la falta de pertinencia de la escuela como institución frente a la evolución de las sociedades, campos de aburrimiento que se entrelazan con libertades y se encuentran con lo inútil de la forma, del cómo y del dónde, en una función disciplinadora y homogeneizadora evidenciando el abandono del principio de neutralidad (Milstein, 2009). Muchos de estos estudios han aterrizado en propuestas curriculares para buscar posibles salidas y nuevos caminos, sin embargo, se ven encerrados en sus propias versiones metodológicas al tratar de responder desde su quehacer a las concepciones de evaluación que miden y categorizan la educación en nuestro país y es una realidad actual que desde la niñez, la cultura muestra como deber ser que el infante asista a la escuela y el tiempo "libre" lo dedique al juego y al consumismo (Pedraza, 2007), por lo tanto, desde la infancia se modela una persona/cuerpo educado.

Para disertar un poco este punto de partida está desde Assman (2002) una primera relación: aprender/vivir: "¿cómo y cuándo vale la pena el riesgo de soñar con lo imposible, porque las murallas de lo inmediato nos ahogan (aprender a soñar)?; ¿cómo y cuándo tenemos que preocuparnos por la viabilidad de aquello a lo que aluden los sueños? Todo esto, es evidente, va referido a la unidad entre aprender y vivir" (p.75).

Como expresa Assman (2002) el comprender vivir como algo natural, daría lugar a que aprender, al ser unidad del vivir, también debería serlo. Sin embargo, la desconexión que se vive en la escuela está mucho más allá de naturalizar lo "in-naturizable", con este término se hace referencia a los procesos que no corresponden a lo biológico/cosmogónico ni social pero que han sido adoptados por las culturas e incorporados como el deber ser; años de experiencias centradas en lo cognoscitivo, como si este hiciera parte de un cuerpo apto para la escuela, mientras que lo sensible y lo biológico fuese relegado a otro cuerpo, procesos evaluados desde lo comportamental, afectivo y cognoscitivo como si una misma persona tuviera tres variables que tejer en la construcción de aprendizajes, cada una independiente de la otra.

La educación hoy fragmenta las comprensiones de cuerpo, cuerpo por un lado y mente por otro, disyunción fundamentada por primera vez de modo sistemático y explícito por Descartes, al enunciar la dualidad de la sustancia: hay una escisión entre res cogitans 
(sustancia pensante) y res extensa (sustancia extensa) (Descartes, 1968) y se habla de educación integral, sumado a esto, campos relacionados a la vida como la religión y la economía se han encargado de crear nuevos lenguajes de fragmentación, manipuladores/manipulados que hacen de la libertad individual añicos (Bauman, 2006).

Así lo evidencia Najmanovich (2008) en el artículo sobre el conocimiento del cuerpo cuando afirma que Descartes fue uno de los actores más destacados de este proceso de construcción de la experiencia moderna del cuerpo separado de la vida y del alma, y posteriormente cita:

Examiné atentamente lo que yo era, y viendo que podía fingir que no tenía cuerpo alguno y que no había mundo ni lugar alguno en el que yo me encontrase, pero que no podía fingir por ello que yo no fuese, sino al contrario, por lo mismo que pensaba en dudar de la verdad de las otras cosas, se seguía muy cierta y evidentemente que yo era, mientras que, con sólo dejar de pensar, aunque todo lo demás que había imaginado fuese verdad, no tenía ya razón alguna para creer que yo era, conocí por ello que yo era una sustancia cuya esencia y naturaleza toda es pensar, y que no necesita, para ser, de lugar alguno, ni depende de cosa alguna material; de suerte que este yo, es decir, el alma, por la cual yo soy lo que soy, es enteramente distinta del cuerpo y hasta más fácil de conocer que éste $y$, aunque el cuerpo no fuese, el alma no dejaría de ser cuanto es (p.8).

La invitación de Najmanovich se funda en el conocer/conocerse como unidad relacionante, situando lo biológico que la ciencia ha demostrado como evidente, y que en ocasiones se desconoce, y se teje con argumentos para evidenciar en el ser lo cuántico, lo cósmico; "la vieja dicotomía cuerpo-mente abren las puertas al pensamiento complejo para producir un abordaje que permita pensar una mente corporalizada y un cuerpo cognitivo corporal." (Najmanovich, 2005, p.23).

Desde esta reflexión de la fragmentación y a partir del tejido que surge desde las comprensiones escuela/aprendizaje desde, con y a través del cuerpo presentan la situación de la escuela del presente.

\section{Método}

En esta revisión al trasegar la investigación desde el pensamiento complejo, donde el método y la teorización como comprensiones van en retroacción y resonancia, donde lo antagónico tiene lugar y lo observado contiene al observador, evidencia varias nociones que permiten que el tejido y su teorización sean rigurosos dentro del pensamiento científico, la manera en que se observa la escuela supone un estado de conciencia, en palabras de Maturana (2004) " el observar como una operación humana que requiere del lenguaje y presupone la conciencia de estar observando algo en ese momento" (p.21), así, la manera en que se reconstruye la realidad al ser observada requiere un método/metódica que permita fluir de forma transdisciplinar, que como lo expresan Martínez, Rivera (2020): " los métodos posibilitan, favorecen o privilegian ciertas maneras de conocer la realidad social, y, al mismo tiempo, restringen, limitan o subestiman otros 
procedimientos". La comprensión del método es definitiva para la comprensión del problema de estudio, referentes acuñados en la construcción en Luengo, citado por Cardona (2019) plantea diversos niveles de comprensión del método en esta lógica:

Método como episteme: construcción de principios, disposiciones y categorías lógicometodológicas en el proceso de conocimiento; Método como proceso estratégico: proceso establecido a partir de inferencias de los principios y disposiciones epistémicas que permiten estratégicamente avanzar en el conocimiento empírico de la realidad; Método como práctica (metodología): uso de procedimientos e instrumentos de investigación (técnicas o herramientas) sobre el ámbito de la realidad que se investiga o problematiza; Método como cognición: estrategia reflexiva y crítica del sujeto-investigador (sujeto epistémico o cognoscente) que piensa en, sobre y durante su acción cognitiva. Es decir, sobre la aplicación epistémica, estratégica y práctica de la investigación (p.44)

Se configura el trasegar por el conocimiento en bucle evidenciado en múltiples campos de pensamiento con rigor científico (Maldonado, 2006) entramando desde el lenguaje formas de hilar las comprensiones del bucle escuela/aprendizaje desde posturas relacionantes con/en/a través del cuerpo; el diseño metodológico: metódica/metodologías, en tanto no es una herramienta rígida ni apartada de la teorización, tiene relación constante con las teorías que nutren esta experiencia y está en dialogicidad constante con lo estocástico y la experiencia de la investigadora implicada, así en triangulaciones constantes se va profundizando el problema y desde la estética y los principios del pensamiento complejo se teje de forma dinámica y transdisciplinar el conocimiento, como afirma Cardona (2019) "Con razón, Morín, gran maestro de la complejidad -y a criterio del sujeto actor / autor de esta obra-, es quien, una vez más, alerta sobre la necesidad del pensamiento complejo para comprender los problemas radicales de la sociedad- mundo, que, en esencia, son aquellos que el nuevo paradigma convoca transdisciplinariedad del conocimiento humano" (p. 35).

Estas comprensiones están basadas en los tejidos de problemas profundos en donde la corporeidad y la corporalidad, la relación excéntrica en cómo ser, estar y tener un cuerpo hacen parte de la percepción de la realidad de cada persona y las formas de acercarse al aprendizaje; el meta observar el aprendizaje desde una pedagogía corporeizada y así, a partir de este tejido en profundidad, posibilitar el reencuentro desde el equipaje histórico de la educación en Colombia y las didácticas que han tenido lugar y que llevan a las bifurcaciones y nudos que dan paso a los aprendizajes.

El camino hasta el momento y su proyección evidencian los siguientes trayectos:

- $\quad$ Tejidos de cuerpo/aprendizaje que han tenido lugar en la escuela hoy a la luz de la pregunta de conocimiento y las interacciones dialógicas de la misma.

- $\quad$ Hilación del bucle en retroacción a la pregunta de conocimiento.

- $\quad$ Comprensiones en complejidad y trasegar conceptual de postura relacionante: Cuerpo y sus articulaciones en campos de conocimiento y el problema crucial: Aprendizaje 
- Interacciones desde las posturas disciplinares en develar complejo desde los sistemas dinámicos y la transdisciplinariedad.

- $\quad$ Relaciones disciplinares en despliegue al problema crucial y postura relacionante para el tejido de problemas en profundidad.

- $\quad$ Comprensiones de cada problema profundo a las luces de las teorías y el dato empírico que den paso a una discusión que entreteja posturas críticas frente a los intereses gnoseológicos de la investigación que convoca y permitan pasar de la analítica a la sistémica en campos de conocimiento.

- Discusiones teorizadas con conjeturas que permitan el inicio de la construcción de nuevo conocimiento teorizado alrededor de mediación, enacción y bioaprendizaje.

Si bien el problema se construye desde dialogicidades entre autores teniendo en cuenta el contexto actual y la mirada de la investigadora, hay un grupo de convocados a implicarse en la investigación desde sus testimonios vitales, mediante el trasegar por mapas de conocimiento; estos mapas, presentan sin jerarquías las palabras claves de la investigación con preguntas dialógicas que orienten la construcción de la experiencia desde al diálogo, de este modo, los implicados podrán tomar el camino discursivo que más se ajuste a su percepción y la investigadora podrá triangular esta información en dialogicidad con el contexto y los autores convocados, Najmanovich(2006) expresa que la reflexión funda todo el conocimiento del sujeto en la experiencia, en las imágenes percibidas y reproducidas por sí mismos.

\section{Desarrollo y Discusión}

El trasegar conceptual de esta investigación intentará evidenciar comprensiones de la escuela como institución en interacción con el cuerpo y cómo este es concebido frente a los aprendizajes, así, el inicio de la comprensión es la esencia de la escuela, sus estudiantes, quienes disponen su cuerpo para el aprendizaje y cómo ellos en sus diferencias físicas, culturales, emocionales, familiares, entre otras, son comprendidos como parte de un grado de acuerdo a su edad y es definido su desarrollo de acuerdo a procesos curriculares previamente establecidos sin discriminar para cada uno el qué, cómo y para qué se quiere aprender. En otras palabras, el estudiante "tiene que hacer coincidir sus proyectos personales con los proyectos del maestro que no son sino los de la sociedad que lo mantiene" (Gutiérrez, 1984, p.53). 
Figura 1.

Isométrica de concepciones iniciales. Concepciones iniciales

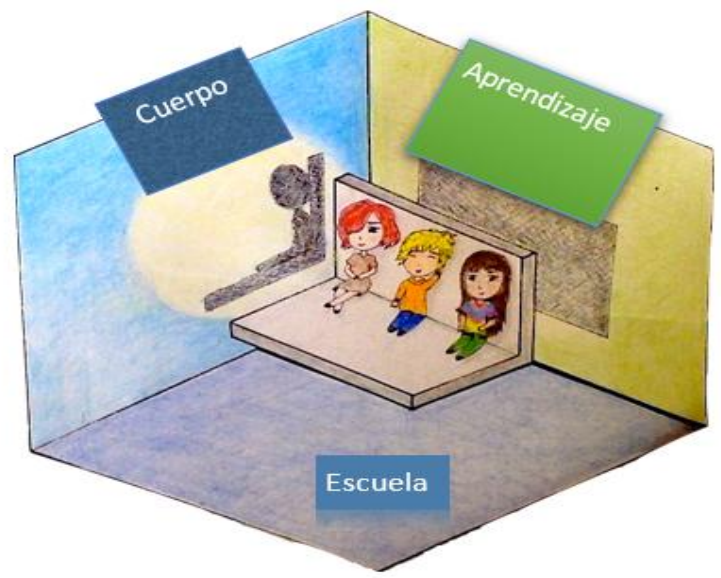

Creación de Laura Londoño/ Diana Carolina Ortiz Tomada de Ortiz, (2020, p.29).

En el atractor epistémico es visible como para los actores de la escuela, el aprendizaje y el cuerpo hacen parte de un reflejo colectivo y no es reconocido desde las particularidades de sus actores, así estos dos reflejos iniciales (cuerpo-aprendizaje) se constituyen en las primeras construcciones conceptuales de esta investigación.

\section{El cuerpo/aprendizaje, un problema profundo, un problema crucial.}

Las maneras como los análisis separan el objeto del sujeto (Maldonado, 2011) y la comprensión del aprendizaje como algo externo a lo corporal, han creado fragmentaciones del conocimiento desde la forma en cómo se aprende, a través de qué se aprende y la función del aprendizaje, así, fácilmente un estudiante considera su experiencia de aprendizaje como la comprensión de algo externo a sí mismo, o más común aún, un proceso exclusivamente de la mente, del pensamiento, convirtiendo a las personas en juguetes científicos (Illich, 1978b). De estas reflexiones, experiencias y miradas de la educación, la investigación ha llevado al cuestionamiento profundo que ha permitido abrir nuevos interrogantes, nuevos horizontes, por ejemplo, ¿qué experiencias de aprendizaje puede alejarse del cuerpo?, ¿qué cuerpo tiene lugar en el aprendizaje para el diseño de la escuela de hoy?, ¿cómo es la comprensión del cuerpo en la escuela dentro de los procesos educativos? El cuerpo, nuestro cuerpo, es entendido desde el somos/ tenemos/estamos (Berger, Luckmann, 1967) ¿cómo comprender esa relación excéntrica? Si los procesos de aprendizaje en la escuela fuesen comprendidos desde la corporalidad, cada aprendizaje nos acercaría más al conocimiento de nosotros mismos, dicho en palabras de Bourdieu (citado por Milstein, 1999): "Lo que se aprende en el cuerpo no es algo que se posee como un saber que uno puede mantener delante de sí sino algo que se es" (p.20). Esto permite crear una triangulación a partir del cuerpo, un ser, un estar y un tener, ver figura 2. 


\section{Figura 2.}

Triángulo virtuoso: Cuerpo

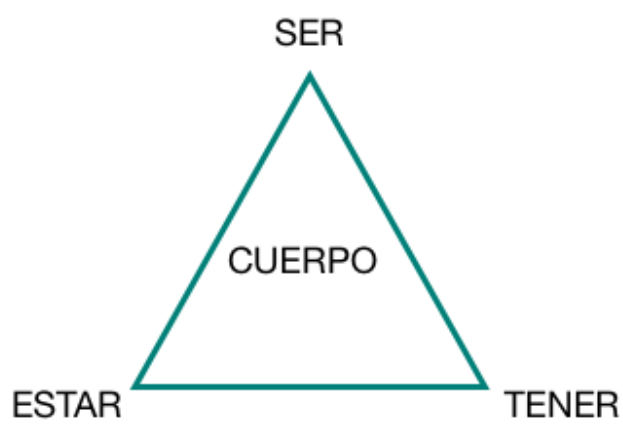

Fuente: Elaboración propia a partir de Ortiz, (2020, p.62).

Así, se comprende el cuerpo como sistema abierto agregando que, los investigadores, para abordar un método desde la complejidad también deben tener una disposición abierta (Maldonado, 2015). La figura 3 está constituida como campos de pensamiento (Maldonado, 2014), para hilar el triángulo virtuoso desde lo hologramático a la experiencia vital/ la vivencia escolar, como sugiere Morin (2006) visión hologramática/ visión universal.

Figura 3.

Mapa de conocimiento: Articulaciones- Postura relacionante: Cuerpo

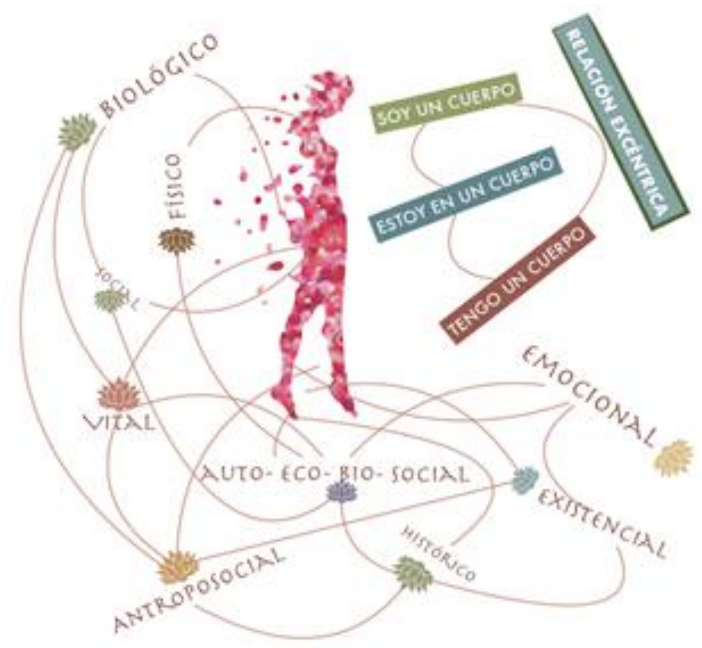

Fuente: Elaboración propia a partir de Ortiz, (2020, p.72).

En este mapa de conocimiento se muestra cómo el tejido ha develado en la construcción del problema religa la comprensión excéntrica del cuerpo en articulación con disciplinas y comprensiones epistémicas que permiten ampliar y profundizar las dialogicidades de cuerpo hacia la generatividad del conocimiento. 


\section{Somos átomos, somos un cuerpo, somos cosmos}

"Aún no se ha tomado conciencia de que lo visible es parte de lo invisible" (Boff, 2002, p. 24).

Reconocerse desde lo visible/invisible no parece ser de interés para una gran parte de los seres humanos. En este epígrafe Boff invita a comprender el cuerpo desde el pensamiento complejo, así, el tomar conciencia de que el cuerpo es visible hasta cuando los ojos están cerrados, y que la comprensión implica percepciones epistémicas desde la mismidad como un sistema abierto (Eisler, 1991). El cuerpo que resuena con que el cuerpo físico y el no físico, que puede explicarse desde lo cuántico cuando se construyen percepciones de lo que se es a partir de lo visible para los seres humanos, el percibirse en el cuerpo desde las partículas más pequeñas cuando se entrelazan y transforman con lo "invisible", es ser conciencia universal, ser red creadora (Payán, 2000).

Es así como ser un cuerpo es ser piel, huesos, órganos, fluidos, células, membranas, elementos químicos, ondas, iones, átomos, partículas... todo lo que es ser cuerpo, está siendo constantemente, no hay quietud, cada partícula está conociendo, adaptándose, construyendo y esto se hace perceptible; el cuerpo no físico, surge de cada relación, de cada red, es la experiencia, el pensamiento, la emoción, los sueños, el sentimiento, la razón, (Maturana, Porksen, 2004). El punto crucial donde se es un cuerpo es precisamente ese entrelazamiento de lo visible con lo invisible, la enacción, el punto de posibilidades. Ahora bien, ¿qué comprensión dentro del ser un cuerpo se tiene en la escuela? Será necesario refundirla (Morin, 1990) desde sus elementos primarios.

La experiencia en la escuela como institución urbana fracciona los procesos de aprendizaje en dimensiones y considera al cuerpo visible un elemento pasivo en la gran mayoría de los currículos escolares: "En vez de pensar el todo como la suma de las partes, pensémoslo como aquello que aflora bajo el disfraz del caos cada vez que los científicos intentan separar y medir sistemas dinámicos como si estuvieran compuestos por partes" (Briggs \& Peat, 1990, p.72).

Una de las expresiones que demuestra el poder atómico en resonancia con el universo y puede hacer evidente que la piel no es el límite del cuerpo sino una posibilidad es el lenguaje (Calvo, s.f.), aquel con el que se es creador de realidades (Maturana, 1995). El lenguaje como una forma de cuidado del cuerpo desde lo visible, el lenguajear como acto responsable y provisto de significados, hacer del lenguaje codificado una herramienta transformadora. Si en el ejercicio del educar las comunidades aprendientes (Gutierrez \& Prado, 2006) se fortalece la ética de la comunicación como elemento fundamental para sostener relaciones respetuosas y constructivas, muchos de los problemas psico- sociales que afectan la escuela y por ende a las comunidades dejarían de ser porque carecerían de significado, el lenguaje bien modelado, como hábito de conservación puede ser la herramienta más potente de construcción social.

Si el conocimiento fuese tejido desde el ser y no desde el haber con una comprensión corporalizada y corpórea del aprendizaje, si este fuera posible para la unidad de los 
cuerpos como sistemas abiertos, si el educar y el estar en la escuela fuese un rito y no una rutina (Cosachov, 2000).

\section{Tener un cuerpo: aprendizajes y cultura}

"El cuerpo ha abandonado el terreno de lo natural para ser una más de las tareas culturales del mundo contemporáneo" (Pedraza, 2004, p.25).

Tener un cuerpo responde a una construcción diferente, a una construcción de la cultura, a una construcción desde la educación. Tener un cuerpo se ha convertido en el objetivo de "vida" para muchas personas, la cultura ha creado prototipos de cuerpos físicos y formas de interacción de los cuerpos predefinidas socialmente que le transforman el pensamiento a las personas, tanto así, que la "otra" parte de cuerpo, la invisible, pasa a ser un acompañante totalmente manipulable.

En este momento el entendimiento del cuerpo desde el tener es tan nocivo, que individuos y sistemas determinan socialmente quien se debe ser basándose en esos prototipos de lo que es bello, de lo que es saludable, de lo que es exitoso, pre-conceptos heredados culturalmente y mantenidos por los sistemas de dominación y creados también por el ser humano en su afán de sentir que tienen un cuerpo, en su afán de "lo suyo". Pedraza (1999) expresa como los prototipos corporales han influenciado y degradado el mestizaje:

¿Cómo alcanzar con cuerpos tan defectuosos el ansiado progreso, pragmático como el estadounidense, encantador como el francés, eficiente como el alemán, cortés como el inglés, sobrio y señorial como el castellano? Higiene, alimentación, deporte, educación, vestido y modales, amén de habilidad, ingenio, sensibilidad y técnica conjurarían la maldición del mestizaje colombiano (p.18)

Es acá donde vivir teniendo un cuerpo en esta época y en este contexto, no sólo genera desconocimiento sino rupturas de un sistema de red de redes y es aquí donde "tener un cuerpo" se convierte en entropía: "Segunda ley termodinámica: Entropía: Cualquier sistema físico aislado tomará espontáneamente el camino del desorden cada vez mayor" (Capra, 1992, p.37).

Como lo afirma Capra (1992), el individuo al alejarse de su sistema, hace que lo significante sea tan propio de sí que carezca de sentido en lo colectivo, crea desorden, entendiéndolo como las estructuras que crecen pero no se cualifican, se multiplican experiencias/nudos/bifurcaciones sin vértices que sostengan la estructura (Briggs, Peat, 1999), alimentándose los procesos de evolución cultural sin cooperación, excluyentes, marginales, que no hacen sino clasificar a las personas y jerarquizarlas a través de macroestructuras de poder que naturalizan formas de vida desde el deber ser, el deber tener... el deber haber.

Aun cuando el pensamiento científico ha evolucionado para darle sentido al ser humano evidenciando otras formas de relacionarse más biológicas, más humanas, en interconexión 
como sistemas fractales (Morin, 1999) con teorías como el principio de la incertidumbre, la física cuántica y las leyes de la termodinámica, la convivencia de las personas se quedó en las formas de vida mecánicas y estas se reproducen día a día en la escuela (Gutierrez \& Prado, 1997). Ahora bien, ¿cómo se viven estas teorías en ámbitos educativos para que lo que se aprenda en y a través el cuerpo responda a un tener que se vincula con con la posesión jerarquizante y capitalista? (Lugones, 2008).

El tener un cuerpo es entonces una posesión de cada ser humano, se es y se está si se tiene un cuerpo, y aunque la reflexión se torne hacia la falta de cuidado de este (Hathaway y Boff, 2009) y el exceso de manipulación que se tiene educativa y culturalmente sobre el mismo desde la escuela como institución, tener un cuerpo representa una responsabilidad desde la ética con la naturaleza, el multiverso y con la misma especie (Osorio, 2008).

\section{Estar en un cuerpo/cuerpo objeto}

'La disposición y la interpretación de las tareas y hábitos corporales que constituyen la vida cotidiana revelan los principios ideológicos cuya condición se naturaliza precisamente porque involucran el cuerpo" (Pedraza, 2006, p.94).

El cuerpo está continuamente en el proceso del conocer, vive inmerso en un proceso de aprendizaje constante basado en relaciones e interacciones con el ambiente, el cuerpo constantemente está fortaleciéndose en su identidad y construyendo alrededor de ella significados, es así, como el estar en un cuerpo tiene que ver con las interacciones que hace el cuerpo para conocer, y si el cuerpo interactúa tal cual dice Capra (1996) como una red dentro de otra red, como si se tratara de un fractal, ¿con qué tipos de redes interactúan los cuerpos que habitan la escuela hoy? Illich (1978a) describe de una manera muy sucinta estas interacciones:

La escuela forma a un estudiante pasivo y competitivo que lo único que le interesa es escalar en la esfera social para poder llegar a tener mansiones lujosas y derrochar el dinero en esos centros del consumismo llamados centros comerciales. El estudiante se moldea así un mundo diferente en su mente donde el ansia de comprar y convertir en mercancía su conocimiento es requisito para pertenecer a la moderna sociedad (párr.2)

Los seres humanos en su experiencia vital están tan objetivados como cuerpo y como naturaleza, que consideran normal en el proceso de evolución que lo sustentable sea la economía del dinero y no el planeta (Sheldrake, 1991); aguas contaminadas, explotaciones mineras, bosques talados, capa de ozono cada vez más delgada, entre otras lesiones, son el resultado del modelo económico actual y en su consecuencia del modelo educativo y cultural. Así lo refuerza Bohm (2008):

Totalidad No Dividida en Movimiento Fluyente. Esta manera de ver supone que el flujo es, en cierto sentido, previo a las «cosas» que vemos formarse y disolverse en dicho flujo. Tal vez se podría ilustrar mejor lo que se intenta decir aquí considerando la «corriente de la consciencia». Este flujo de atención no es definible con precisión $y$, sin embargo, es previo a las formas definibles de pensamientos e ideas que 
podemos ver formarse y disolverse en su flujo, como rizos, ondas y remolinos en una corriente que fluye (p.12)

Se está pensando la escuela como la totalidad, las relaciones que se dan como aquel flujo, y en los rizos, las ondas y los remolinos como los sujetos que participan de esas relaciones, cada cual, con su genética cultural, su historia, su sueño, en un intento por aprender y disolverse acercándose a formas de tejer el conocimiento.

Este sería el ideal, sin embargo, la situación en la escuela responde a algo mecánico lleno de paradigmas desde la simplicidad (Najmanovich, 1994) y sin importar los elementos visibles que se expresan a través del cuerpo -como emociones, condición sexual, identidad étnica, estética social y cultural y menos aún aquellos elementos invisibles- la escuela actúa sobre el estudiante como si toda esa corriente de flujos fueran en la misma dirección, en el mismo espacio y a la misma velocidad, respondiendo en muchas ocasiones a los intereses de otros, a un orden social, cultural, ecológico, político y económico impuesto desde la colonización y que desconoce otras formas con las que se relacionaban nuestras raíces, incluso órdenes impuestos diferentes a los ciclos propios de la naturaleza, de la mujer y de la vida (Novo, 2007).

Es así como el estar en un cuerpo representa estar en una sociedad, hacer parte de una herencia cultural y el aprendizaje debe resonar con el cómo convivir en el contexto donde el cuerpo está inmerso, y es en este punto donde la escuela tiene el control, el deber ser, el deber haber y el deber estar... deberes que corresponden a lo planteado por Jiménez López en sus discursos para inaugurar la modernidad y el debate eugenésico donde sencillamente expresa dentro de ese deber ser/haber/estar qué y cómo es lo bello/adecuado/aceptable (Pedraza, 1996) y aún más, es tan cerrado el bucle escuela/aprendizaje/cuerpo que la escuela siendo en sí misma un ente de control, es controlada por otros poderes: económicos, políticos, religiosos, sociales, morales y éticos. En esta reflexión hay cantidad de ejemplos de subordinación, de control, de miedo para que el resultado en el aprendizaje sea el que describe Gutiérrez (1984):

Por la paciencia el niño aprende a adaptarse a las exigencias de la vida, aprende a dominar sus impulsos, a reprimir sus potencialidades y a controlar sus más genuinas manifestaciones humanas. Muy pronto aprende que si quiere vivir en paz tiene que contener a raya sus emociones y sentimientos y tiene que actuar con la mayor racionalidad, tal y como los adultos esperan de él. En otras palabras, tiene que hacer coincidir sus proyectos personales con los proyectos del maestro que no son sino los de la sociedad que lo mantiene (p.53)

Se convierte el estar en un cuerpo para la escuela y los actores que en ella interactúan en un círculo vicioso, inútil, sin sentido para algunos, sin rizoma para la mayoría de la sociedad actual y por lo tanto, el conocimiento, al responder a estos órdenes, en una fragmentación que rinde culto al control, un cuerpo coartado de su libertad, disciplinado/ maquinizado/ medicado (Baudrillard, 1972). Queda de esta observación preguntar ¿cuándo el vivir se ha convertido en un ciclo des-humanizante? 


\section{Problema crucial: Aprendizaje}

Pensar el aprendizaje como problema crucial de esta investigación, inicia en un recorrido histórico desde Descartes que se ha ilustrado anteriormente en su fragmentación, continúa en un trasegar desde lo cultural e histórico, pasando por frases educativas de peso en los sesenta como "la letra con sangre entra" (Saénz, Saldarriaga \& Ospina, 1997) y descansa en la dialogicidad desde el campo social y político evidenciando la relación de estos con la evaluación del aprendizaje: "El sistema educativo premia el comportamiento competitivo y no la cooperación" (Capra, 1992, p.23). "La competencia es un fenómeno humano; es un fenómeno de relaciones humanas en la cual la emoción central tiene que ver con la negación del otro" (Maturana, 1990, p.96); Así el problema crucial se va tejiendo y delimita las formas de comprender las pedagogías posibles en estas interacciones evidenciando su desconexión con la vida y con lo vivo, como lo muestra la figura 4:

Figura 4.

Problema crucial- Aprendizaje

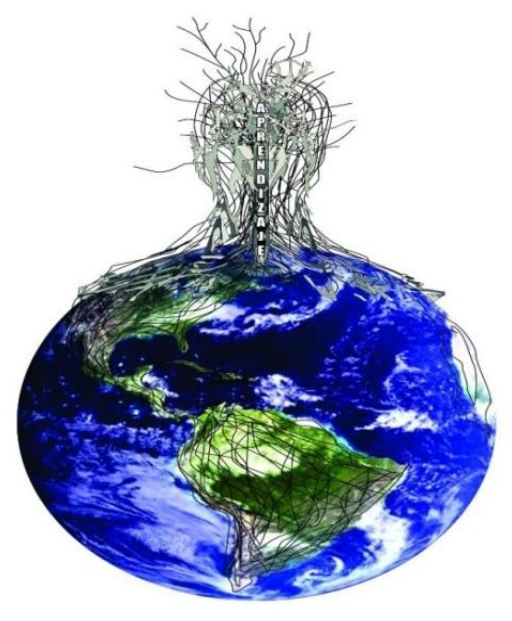

Fuente: Tomada de Ortiz, (2020, p.86).

\section{Relaciones entre el cuerpo y pedagogía en la Escuela hoy}

[...] la sociedad que se había atrevido a extender los horizontes del enclaustrado mundo medieval, pronto remplazó los muros monacales por las coordenadas cartesianas y los sistemas mecánicos que con el tiempo resultaron tan opresivos como las paredes de los conventos... desde los modales y protocolos sociales hasta las prácticas políticas; desde la concepción del espacio plasmada en la cuadrícula de las ciudades "planificadas" hasta las distinciones entre los ámbitos público y privado (Najmanovich, 2016, p.3). 
En Colombia se tiene un legado pedagógico corporal desde que terminó la guerra de los mil días en 1903, la Ley Uribe y la Ley Orgánica de Instrucción Pública, se encargó de promover la educación práctica como la educación dada a los pobres para el sostenimiento económico del país, esa pugna por el control de la educación dibujada con el darle a la escuela la función de restauración social (Saenz, Saldarriaga, Ospina, 1997), reforma tras reforma se sigue viviendo en esta sociedad, el Estado no ha querido perder el control de su gente y controlar la educación es una de las herramientas más poderosas que posee para lograrlo. "No es pertinente hablar de la educación en abstracto, conviene más referirse a prácticas educativas; es decir, a actos humanos intencionales que se presentan como una realidad fenoménica" (Arriaga, 2017, p.273).

Así es la educación en gran parte del mundo: el conjunto de actos humanos que aun queriendo salir del círculo vicioso terminan dominados por las intenciones de ciertos órdenes. Infortunadamente, la educación en este país hace parte de esa institucionalidad que se encarga de enseñar una mirada hegemónica eurocentrista, una educación instruccional que logra cubrir sutilmente objetivos políticos, económicos y religiosos enmascarándolos en cientos de modelos pedagógicos que al igual que la Ley general de Educación (1994), suenan muy bien, se sustentan de forma transformadora en el lenguaje, pero que, dentro de la escuela, no dejan de ser quiméricos.

La escuela en su actual organización, estructura métodos didácticos y mantiene en plena vigencia la ley del más fuerte y el sálvese quien pueda que, como se sabe, es un norte primordial de la sociedad capitalista (Gutiérrez, 1984, p.46).

En consonancia a esta reflexión, el cuerpo es educado o disciplinado para estos fines, el lugar que ocupa el cuerpo de la niñez en el espacio escolar colombiano y el cómo las prácticas pedagógicas desconocen lo invisible, jerarquizando, violentando y reproduciendo modelos capitalistas, la educación corporal del país es un mecanismo de colonización, y como lo afirmara Quijano (2000): "[...] colonialidad no se refiere solo a la clasificación racial, se refiere a la producción del conocimiento que ocurre en la interrelación entre sexo, subjetividad, autoridad y trabajo, y todas las relaciones de poder que esconden" (p.343).

Es en este sentido como el cuerpo educado ha estado inmerso en ideales del haber, que lo comparan perdiendo su unicidad, su identidad propia (Bohm, 1987), volviéndolo competitivo, con mayor deseo de parecerse a los otros que de conocerse a sí mismo o la negación por desconocimiento de sí mismos.

El tener tan arraigado, tan propio de sí el término competencia no solo crea desequilibrios en la misma especie, sino que conduce a que el antropocentrismo en el ser humano desprecie la naturaleza (Grosfoguel, 2006) y se sienta mejor que los demás organismos, sobreponiendo el tener un cuerpo. Así lo refuerza Pedraza (2010):

El cuerpo que se ha convertido en campo de batalla, en fundamento de la subjetividad, en terreno existencial de la cultura y en promesa de emancipación, es el resultado de la conjunción de formas de conocimiento y de prácticas capaces de 
construir aspectos centrales de las formas de vida de las sociedades contemporáneas (p.15).

Este fenómeno competitivo/educativo/corporal basado en el disciplinamiento con fines específicos junto al crecimiento tecnológico ha llevado a la persona a una deshumanización, si bien en este punto bien se podría proponer toda una teoría del aprendizaje por medios 'artificiales', refiriéndose a sistemas no autopoiéticos, a artefactos, a inteligencias artificiales, a redes de redes creadas para organizar y clasificar la información, estructuras a través de las cuales también puede percibirse el conocimiento, asertivamente lo expone Panikkar: "Hoy el universo tecnológico es más potente que el universo natural" (1994, p.14), sin embargo, la intención de hilar las formas de conocer a través del cuerpo al interactuar con el ambiente responden a la esperanza de transformación, como lo expresa Varela con respecto a lo que está y lo que no está vivo: "(...) podemos decir que un sistema físico está vivo cuando es capaz de transformar la materia/energía externa en un proceso interno de automantención y autogeneración" (Varela, 2002, p.27).

Si bien la educación debe reinventarse (Morin, 1999) y el camino de lo tecnológico suena bastante innovador, la desconexión del ser humano con el cosmos, con lo vivo, consigo mismo, con su corporalidad, con su esencia... ha llevado al sinsentido y al riesgo de extinguir la especie, como dice Gutiérrez (1996), "O cambiamos o desaparecemos".

El cuidado del cuerpo, al igual que el cuidado de la naturaleza, es indispensable para que se preserve la especie, la morfogénesis del conocimiento (Morin, 1999, p.44) -relación entre enseñar y aprender-debería estar en consonancia con este fin. El cuidado desde el conocerse y el meta-observarse (Maturana, Varela, 2004) en busca de una estabilidad que solo es posible si se previene la agresión en contra de la naturaleza y del cuerpo, dinamizando relaciones y correlaciones que sensibilicen, aprecien, reivindiquen la sociedad como comunidad, como familia, como especie; suavizando nudos que no permiten el tejido asertivo como el capitalismo desmedido, consumismo, racismo y tantos otros que se han insertado en las escuelas quitándole sentido al aprendizaje.

Cada experiencia que tenga lugar desde el cuerpo o en el cuerpo, será una experiencia responsable (Maturana, 1999) en cuanto a las consecuencias de la experiencia misma en términos de aprendizajes, que el conocimiento dependa "de estar en un mundo inseparable del cuerpo, el lenguaje y la historia social, síntesis, de nuestra corporización" (Varela, Thompson., Rosch, 1997, p.176), que sea parte del educar que lo sustentable sea como lo expresa Roszak (1994) "los derechos de la persona son los derechos del planeta" (p.80), que la humanidad sea consciente de los tejidos de la escuela/cuerpo/pedagogía y así tengan sentido, reflexión y una estética significante (Marina, 1992). 
Figura 5.

Triángulo virtuoso: "Aprendizaje"

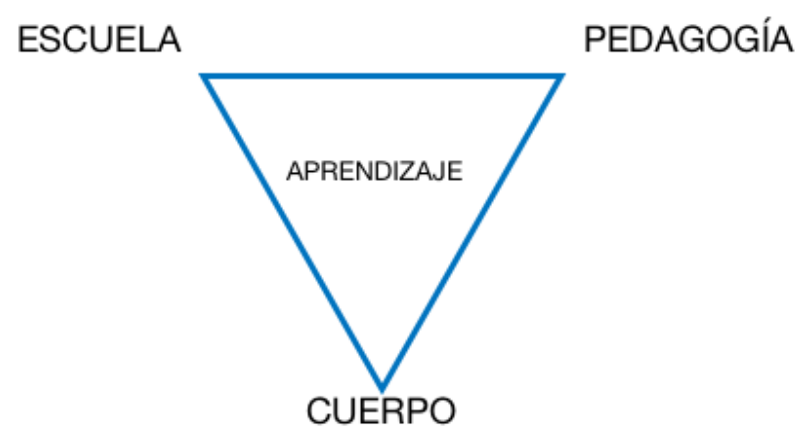

Fuente: Elaboración propia (2020).

Esta comprensión ha dejado ver la profunda necesidad de una ética de religar (Morín, 2006) que supere las dicotomías y separaciones subordinantes de los sujetos, permitiendo la emergencia de subjetividades de alteridad en el encuentro (Brenes, 2012) y el reconocimiento de la diferencia, las formas del aprendizaje y cómo este interviene evidentemente en los procesos culturales que transforman el cuerpo, el concepto que tienen relación directa con sus espacios de formación. Las articulaciones que hacen del cuerpo y la pedagogía cercana o lejana a la humanidad y los humanismos que se entretejen alrededor de los procesos de aprendizaje en la escuela, o al menos los que deben tejer.

\section{Conclusiones y recomendaciones}

El religar con rigor científico lo estocástico y los algoritmos naturales o disipativos en las comprensiones del cuerpo para la construcción de aprendizajes en las escuelas hoy, invita a quienes actúan en la educación a comprensiones transdisciplinares y sistémicas que desde el pensamiento complejo permiten construir nuevos conocimientos en resonancia con las experiencias y necesidades vitales de la comunidad educativa.

Trasegar en el ámbito educativo desde el cuerpo, convoca a pensar la educación como territorio vital, el cuerpo que desde sus múltiples lenguajes perfila su existencia en una construcción estética que amplia en comprensión compleja las relaciones entre experiencias vitales y aprendizajes.

El cuerpo comprendido como algo intrínseco y relacionante en el ser humano y sus vínculos en procesos biológicos/continuos/adaptativos/flexibles desde la experiencia con 
los aprendizajes, permitirán un enactuar con los estudiantes fortaleciendo sus particularidades en escenarios colectivos, usando elementos como la mediación pedagógica, entendida como herramienta transformadora al interior de la escuela de didácticas y posturas de poder que evitan resonancias vitales.

El asumir una racionalidad en comprensión compleja, desde miradas hologramáticas, autopoiéticas y retroactivas puede generar campos de conocimiento desde quienes se interrelacionan entre aprendizaje/pedagogía/cuerpo en las escuelas hoy, formas de pensamiento que develan las comprensiones y permiten construir conocimiento a partir de relaciones cosmogónicas con el universo, la naturaleza y la humanidad fomentando el bioaprendizaje, como aprendizaje para la vida; un aprendizaje para vivir y convivir.

Es crucial la transformación educativa para que sea pertinente a la sociedad actual, la escuela debe abrirse y la pedagogía reinventarse para que quienes habitan los cuerpos en las escuelas hoy, sientan el aprendizaje como algo vital.

\section{Referencias}

Arriaga, J. (2017). Sistema, autopoiesis y entropía en los desafíos educativos contemporáneos. Educación y Humanismo, 19 (33), 271-288. http://dx.doi.org/10.17081/eduhum.19.33.2644

Assman, H. (2002). Placer y ternura en la educación. Hacia una sociedad aprendiente. https://www.revistasinrecreo.com/wp-content/uploads/2015/11/Hugo-AssmanPlacer-y-ternura.pdf

Baudrillard, J. (1972). El más hermoso objeto de consumo: el cuerpo. En Baudrillard, J. La sociedad de consumo: sus mitos, sus estructuras. (págs. 185-213). Barcelona: Plaza \& Janés.

Bauman,

Z.

(2006).

Modernidad

líquida. https://catedraepistemologia.files.wordpress.com/2009/05/modernidad-liquida.pdf

Boff, L. (2002). El cuidado esencial. Ética de lo humano, compasión por la tierra. Madrid: Trotta.

Bohm, D. (2008). La totalidad y el orden implicado. Madrid: Kairós.

Bohm, D (1987). Sobre el diálogo. Madrid: Kairós.

Brenes, C. (2012). Mediación Pedagógica. Condiciones para el aprendizaje vital. (Trabajo de grado, Universidad de la Salle, San José, Costa Rica).

Briggs, J. y Peat, F. (1990). Espejo y Reflejo: Del caos al orden. Guía ilustrada de la teoría del caos y la ciencia de la totalidad. Madrid: Editorial Gedisa.

Briggs, J. y Peat, D. (1999). Las siete leyes del caos. España: Grijalbo. 
Cardona, S. (2019). Humanismos Emergentes Tejiendo Gestión Educativa Territorial En Perspectiva Compleja/Transdisciplinar. (Tesis Posdoctoral, Universidad Simón Bolívar Barranquilla, Colombia). http://bonga.unisimon.edu.co/handle/20.500.12442/5239?show=full

Capra, F. (1992). El punto crucial. (Traducido al español de Theturningpoint). Buenos Aires: Editorial Troquel S.A.

Calvo, L. (S.f). Estudio lingüístico de la Sociedad. http://www.editoriallucina.es/recursos/apps/pdf/Lalia-Agustin-Garcia-Calvo-LaliaEnsayos-de-estudio-linguistico-de-la-sociedad-pdf.pdf

Capra, F. (1996). La Trama de la Vida. Barcelona: Editorial Anagrama.

Congreso de la república de Colombia. (1994, 8 de febrero). Ley 115 de 1994. Diario Oficial no. 41.214. http://www.secretariasenado.gov.co/senado/basedoc/ley_0115_1994.html

Cosachov, M (2000). Entre el cielo y la tierra. Madrid: Editorial Biblos.

Descartes, R. (1968). Meditaciones metafísicas. Barcelona: Espasa Calpe.

Eisler, R. (1991). El Cáliz y la Espada. España: Cuatro Vientos.

Grosfoguel, R. (2006). La descolonización de la economía política y los estudios postcoloniales. Tabula Rasa, 17-48. http://www.scielo.org.co/pdf/tara/n4/n4a02.pdf

Gutiérrez, F. (1984). Educación como praxis política. Madrid: Siglo XXI editores.

Gutiérrez, F. y Prado, C. (1997). Ecopedagogía y ciudadanía planetaria. Costa Rica: Instituto Latinoamericano de pedagogía de la comunicación- Editorial PEC.

Gutiérrez, F. y Prado, C. (2006) Las siete claves de la mediación pedagógica. Costa Rica: Holografías

Gutiérrez, F. y Prieto D. (1996). Mediación Pedagógica. Apuntes para una educación a distancia alternativa. https://ciberinnova.edu.co:10004/archivos/plantilla-ovas1slide/documents-UCN-Canvas/Diplomado-educacion-medios-comunicacion/7mediacion_pedagogica.pdf

Hathaway, M. y Boff, L. (2009). El Tao de la liberación. (Traducido al español de The Tao of Liberation). Madrid: Trotta.

Illich, I. (1978a). La convivenialidad. Barcelona: Ocotepec.

Illich, I. (1978b). La sociedad desescolarizada. (Traducido al español por Gerardo Espinosa). Barral Editores. http://orginsedu.blogspot.com/2014/05/ivan-illichcorina-petronela-gheorghes.html

Lugones, M. (2008). Colonialidad y género. Tabula Rasa, (9), 73-101. https://www.revistatabularasa.org/numero-9/05lugones.pdf 
Maldonado, C. (2006). Ciencias de la complejidad: Ciencias de los cambios súbitos. ODEON, 2(1),87-125 https://revistas.uexternado.edu.co/index.php/odeon/article/view/2643

Maldonado, C. (2011). Termodinámica y Complejidad: Una introducción para ciencias sociales y humanas. Bogotá: Ediciones desde abajo.

Maldonado, C. (2014). ¿Qué es un sistema complejo? Revista Colombiana de Filosofía de la Ciencia, 14 (29) 71 - 93.

Maldonado, C. (2015). Pensar la complejidad, pensar como síntesis. Cinta Moebio, (54), 313-324. https://scielo.conicyt.cl/pdf/cmoebio/n54/a08.pdf

Marina, J. A. (1992). Teoría de la inteligencia creadora. Barcelona: Anagrama.

Martínez-Suárez, A., \& Rivera-Franco, J. (2020). Sistemas fractales como posibilidad para refundar/resignificar sistemas etnoeducativos en Colombia. Educación $y$ Humanismo, 22(38). https://doi.org/10.17081/eduhum.22.38.3679

Maturana, H. (1990). Biología de la cognición y epistemología. Chile: Universidad de la Frontera.

Maturana, H. (1995). Emociones y lenguaje en Educación y Política. Barcelona: Ediciones Dolmen.

Maturana, H. (1999). Transformación en la Convivencia. Barcelona: Dolmen Ediciones S.A.

Maturana, H. y Porksen, B. (2004). Del ser al hacer. Los orígenes de la biología del conocer. Madrid: Lumen.

Maturana, H. y Varela, F. (2004). De Máquinas y seres vivos: autopoiesis, la organización de 10 vivo. $6^{\circ}$ edición. Madrid: Editorial Universitaria Lumen.

Milstein, D. (1999). La escuela en el cuerpo. Estudios sobre el orden escolar y la construcción social de los alumnos en escuelas primarias. España: Unigraf S. L. Móstoles.

Milstein, D. (2009). La Nación en la escuela. Viejas y nuevas tensiones políticas. http://www.memoria.fahce.unlp.edu.ar/art_revistas/pr.5657/pr.5657.pdf

Morin, E. (1990). Introducción al pensamiento complejo. España: Gedisa.

Morin, E. (1999a). La cabeza bien puesta: Repensar la reforma. Reformar el pensamiento. España: Nueva Visión.

Morin, E. (1999b). Los siete saberes necesarios para la educación del futuro. Francia: ONU.

Morin, E. (1999c). El Método III: El conocimiento del conocimiento. Francia: Ediciones Cátedra.

Morin, E. (2006). El Método V: La humanidad de la humanidad. La identidad humana. Madrid: Ediciones Cátedra. 
Morin, E. (2006). El método VI. La ética. España: Ediciones Cátedra.

Najmanovich, D. (1994). El Universo mecánico y el paradigma de la simplicidad. Madrid: Editorial Integral.

Najmanovich, D. (2006). Estética de la complejidad. https://www.researchgate.net/publication/28185707_Estetica_del_pensamiento_co mplejo

Najmanovich, D. (2005). El juego de los vínculos. Subjetividad y redes: figuras en mutación. Buenos Aires: Biblos.

Najmanovich, D. (2008). Mirar con nuevos ojos. Buenos Aires: Ediciones Cátedra.

Najmanovich, D. (2016). El Universo mecánico y el paradigma de la simplicidad. http://convivir-comprender-transformar.com/wp-content/ uploads/2014/09/Clase1-para-imprimir.pdf

Novo, M. (2007). Mujer y medio ambiente: Los caminos de la visibilidad. España: Ediciones Catarata.

Osorio, S. (2008). Bioética y pensamiento complejo. Bioetica, 8 (2), 106-113.

Ortiz, D. (2020). Comprensiones epistémicas del cuerpo que deviene bioaprendizajes: una apuesta desde el pensamiento complejo que cuestiona la escuela del presente (Tesis Doctoral, Universidad Católica de Manizales, Manizales, Colombia).

Panikkar, R. et al. (1994). Nueva Conciencia. Plenitud personal y equilibrio planetario para el Siglo XXI. Madrid: Editorial Integral.

Payán, J. C. (2000). Lánzate al vacío. México: McGraw-Hill.

Pedraza, Z. (1996). El debate eugenésico: una visión de la modernidad en Colombia. Revista de Antropología y Arqueología, (9), 1-2.

Pedraza, Z. (1999). En Cuerpo y alma. Madrid: CORCAS.

Pedraza, Z. (2004). Cuerpo e Investigación en teoría social. Novum, 11 (29), 21-44.

Pedraza, Z. (2006). Modernidad y orden simbólico: cuerpo y biopolítica en América Latina. Revista Aquelarre, (9) 93-108.

Pedraza, Z. (2007) El trabajo infantil en clave colonial: consideraciones histórico antropológicas. Nómadas, (26) 80-90.

Pedraza, Z. (2010). El cuerpo: texto vivo. Construcciones sociales Cuerpo y violencia

¿Genética o cultura? Revista Javeriana, La universidad en diálogo con el mundo, (770), 815.

Peter, B. y Luckman, T. (1967). The Social Construction of Reality. Garden City: Doubleday \& Company. 
Quijano, A. (2000). Colonialidad del poder, eurocentrismo y América Latina. Argentina: Neplanta.

Roszak, T. et al. (1994). Nueva Conciencia. Plenitud personal y equilibrio planetario para el Siglo XXI. Madrid: Editorial Integral.

Sáenz, J. Saldarriaga, O. \& Ospina, A. (1997). Mirar la infancia: pedagogía, moral y modernidad en Colombia, 1903-1946. Bogotá: Universidad de los Andes.

Sheldrake, R. (1991). El renacimiento de la naturaleza. El resurgimiento de la ciencia y de Dios. Madrid: Piadas Ibérica.

Varela, F. (2002). El fenómeno de la vida. Barcelona: Dolmen Océano.

Varela, F., Thompson, E. y Rosch, E. (1997). De cuerpo presente. Las ciencias cognitivas y la experiencia humana. Madrid: Gedisa. 